"Hospital Naval "Almirante Nef". Viña del Mar, Chile.

${ }^{2}$ Centro de Bioética, Facultad de

Medicina Pontificia Universidad

Católica de Chile. Santiago, Chile. ${ }^{3}$ Facultad de Medicina,

Universidad de Chile. Santiago, Chile.

${ }^{4}$ Academia Chilena de Medicina, Instituto de Chile. Santiago, Chile.

Facultad de Medicina, Pontificia Universidad Católica de Chile. Santiago, Chile.

${ }^{5}$ Facultad de Salud, Universidad Santo Tomás. Santiago, Chile. ${ }^{6}$ Clínica Santa María. Santiago,

Chile.

Sin apoyo financiero. Los autores declaran no tener conflictos de interés.

Recibido el 15 de octubre de 2019, aceptado el 6 de diciembre de 2019.

Correspondencia a:

Dr. Carlos Echeverría B. Hospital Naval "Almirante Nef", Subida Alessandri s/n. Viña del Mar, Chile. ciecheverria@hotmail.com

\section{Objeción de conciencia y acciones de salud}

\author{
CARLOS ECHEVERRÍA B. ${ }^{1}$, ALEJANDRO SERANI M. ${ }^{2}$, \\ ANAMARÍA ARRIAGADA U. ${ }^{3}$, ALEJANDRO GOIC G. ${ }^{4}$, \\ ALBERTO ROJAS O. ${ }^{5}$, GONZALO RUIZ-ESQUIDE ${ }^{6}$, \\ RODRIGO SALINAS R. ${ }^{3}$, PAULINA TABOADA R. ${ }^{2}$,
}

CARLOS QUINTANA V. ${ }^{2}$, RICARDO VACAREZZA Y. ${ }^{3}$, a nombre del Grupo de Estudios de Ética Clínica de la Sociedad Médica de Santiago

\section{Conscientious objection in medical actions}

Conscientious Objection arises as a response to a regulation that is judged as immoral. Faced with a law that is considered unfair, the citizen can respond accepting it against his will, exercising conscientious objection on a personal level or, collectively reaching civil disobedience or revolutionary violence. This is an old discussion known since ancient Greece. The current enactment of laws that allow actions previously judged as crime, and that contravene medical tradition, reactivated the discussion about such objection. Some people, such as Savolescu, who denies the legitimacy of conscientious objection invoked by doctors, arguing that it is inefficient, leads to inequality and is inconsistent. He proposes that the values of these professionals can be tolerated privately but should not be determinant in the public sphere. These arguments are critically examined, mentioning pertinent answers from theoretical and practical points of view. We highlight that ethics should not differ in public and private spheres and the principles should be the same, but exercised in different fields. It is concluded that conscientious objection is acquiring legitimacy and that it is necessary to reflect on the underlying reasons that lead to invoke it. It should be considered a civilized resource against determinations of power that are considered to be an attempt against personal values and moral integrity.

(Rev Med Chile 2020; 148: 252-257)

Key words: Conscience; Conscientious Refusal to Treat; Refusal to Treat.
E l ejercicio de la práctica médica en nuestro país se ha visto últimamente interpelado por lo que se ha dado en llamar "la objeción de conciencia". Se trata de un tema clásico,pero de perfiles nuevos y sobre el cual ha habido poca reflexión de fondo, al menos en nuestra profesión.

A raíz de la ley 21.030, que "regula la despenalización de la interrupción voluntaria del embarazo en tres causales" ${ }^{\prime \prime}$, este tema emerge como de genuino interés y acción concreta.

Si bien no se trata de un tema estrictamente médico, en el sentido científico y técnico, es un tema ético, político y legal que incide directamente en aspectos centrales del ejercicio de nuestra profesión. Esto exige de la comunidad médica tanto una reflexión y postura ética, como una repuesta práctica coherente.

\section{Antecedentes}

La "objeción de conciencia" no parece ser,en estricto rigor,una "institución jurídica"sino una acción que se sitúa en el límite de lo jurídico. Ella surge como una respuesta frente a una exigencia normativa cuyo contenido objetivo es juzgado como inmoral. Consecuentemente,el objetor 
niega obediencia a esa norma legal apelando a una instancia superior radicada en su conciencia.

Un problema teórico y práctico complejo se ha planteado en Chile, porque en el caso de la ley de aborto se ha estipulado por ley la posibilidad de sustraerse a su aplicación, acogiéndose a la figura de la objeción de conciencia, en la forma que los textos legales indican ${ }^{2}$. Así, algo que se sustrae a la norma queda, de algún modo, incorporado y legitimado en ella.

La objeción de conciencia se plantea cuando la validez de la norma es cuestionada por parte de uno o más individuos, lo que no responde a la mera conveniencia o al capricho personal, sino a una cuestión fundamental de orden moral. Estamos frente a una situación de radical importancia para los sujetos, que no sólo atañe a aspectos parciales de la vida personal o social. Para los objetores son cuestiones radicales desde el punto de vista ético, porque inciden en el significado total de la existencia y que, por lo tanto, los obliga a intentar sustraerse de toda participación en su aplicación.

Aun cuando solemos tener cuestionamientos con respecto a la justificación de tal o cual norma jurídica particular, esta discrepancia no conduce a una actitud de abierta resistencia, sino que se opta ya sea por padecer lo que se considera una injusticia o por sustraerse lo más posible a su esfera de aplicación. Aquí, en cambio, se trata de una afectación moral fundamental, y no de cualquier objeción moral a una ley. Ello se evidencia por el hecho que, por ejemplo, en el caso particular del aborto, los médicos objetores no sólo estiman vulnerado el sentido de su profesión, sino también su propia moralidad.

Implícito en lo anterior se encuentra el reconocimiento que, si es evidente que la conciencia moral humana puede fallar en lo particular, no suele fallar, sin embargo, cuando de buena fe juzga acerca de las cosas humanas fundamentales ${ }^{3-5}$. Este reconocimiento antropológico está en la base de la concepción política democrática.

En Chile, la Constitución "asegura a todas las personas la libertad de conciencia, la manifestación de todas las creencias y el ejercicio libre de todos los cultos que no se opongan a la moral, a las buenas costumbres o al orden público"' . A su vez, la Declaración Universal de los Derechos Humanos indica, en su artículo $18^{\circ}$, que "Toda persona tiene derecho a la libertad de pensamiento, de conciencia y de religión; este derecho incluye la libertad de cambiar de religión o de creencia, así como la libertad de manifestar su religión o su creencia, individual y colectivamente, tanto en público como en privado, por la enseñanza, la práctica, el culto y la observancia"7.

Las expresiones jurídicas citadas reconocen que los seres humanos vivimos actualmente en grandes conglomerados que admiten en su seno una pluralidad de costumbres, tradiciones y convicciones, pero que, no obstante esa diversidad, subsiste entre ellos la voluntad de vida en común. De hecho, las normativas que se establecen intentan fijar condiciones que hacen posible esa convivencia, a través del mutuo respeto a las convicciones personales fundamentales.

La dificultad moral que subyace a la objeción de conciencia en sí no es nueva y se ha visto repetidamente reflejada a lo largo de la historia tanto en la literatura como en la discusión jurídica y filosófica. La historia abunda en ejemplos de quienes han pagado con prisión o la vida, su negativa a prestar obediencia a una ley considerada éticamente injusta.

En la reflexión filosófica y jurídica este dilema moral aparecía al estudiar lo que le corresponde hacer al ciudadano frente a una ley injusta. Esto es, una ley acerca de la cual algunas personas o grupos cuestionan su validez moral. El positivismo jurídico que reemplaza la noción de ley injusta por la de ley válida o legítima ha contribuido a difuminar esta consideración.

Lo nuevo de la situación en las sociedades occidentales es que, en virtud de esta voluntad de vida en común en la diversidad, ha surgido el ánimo de respetar la disidencia, y no de reprimirla o aplastarla por la fuerza; al menos no por la fuerza física. La objeción de conciencia, como signo de esta actitud social, constituiría entonces una suerte de disposición a enfrentar más civilizadamente estas discrepancias.

\section{La objeción de conciencia en la vida política}

Frente al conflicto entre lo dispuesto por la norma jurídicamente legítima -pero reputada éticamente injusta-, y la propia conciencia moral, se aprecian en la práctica diferentes respuestas que pueden ser caracterizadas esquemáticamente del modo siguiente:

La primera reacción es el sometimiento contra voluntad a la norma, por temor a la fuerza física o psicológica. En este caso las personas, aun no 
estando de acuerdo con la ley injusta, no tienen la capacidad psicológico-moral para resistir la coacción. Esta sumisión -como lo ilustra la historia- suele ser la respuesta mayoritaria, y puede generar un consenso más aparente que real.

La segunda respuesta es la objeción de conciencia, que surge de minorías éticamente consistentes, en sociedades pluralistas. En el uso corriente, como lo ha señalado la RAE en su diccionario, por objeción de conciencia se entiende "la negativa a realizar actos o servicios invocando motivos éticoso religiosos" ${ }^{\prime} \mathrm{o}$, más técnicamente, se la define como un "acto individual, privado, que consiste en transgredir un deber impuesto por el derecho, invocándose para ello por el correspondiente sujeto normativo que su conciencia moral le obliga a ejecutar un acto diferente del mandado por el derecho". Aunque el uso técnico considera que la objeción de conciencia es "un acto individual, privado", no se trata de un acto oculto o clandestino. De hecho, el objetor suele declarar públicamente su insumisión. Además mientras más alta sea la autoridad intelectual y moral del objetor, mayor será el alcance social de su acto. El objetor opone entonces a la fuerza física o psicológica, el testimonio de su propia consistencia moral. Ejemplos históricos de desobediencia individual, por seguir a su conciencia, que sufrieron el rigor de la autoridad serían, entre otros muchos, el caso de Antígona en la tragedia de Sófocles, el de Sócrates en la antigua Atenas, el de los mártires cristianos en la Roma imperial, el de los judíos obligados a convertirse por las monarquías europeas medievales o el de Tomás Moro, jurista y político inglés que rehusó sumisión a las pretensiones ilegítimas de su rey. Acciones, todas ellas,con consecuencia de prisión, muerte o exilio colectivo para sus protagonistas.

Cuando se trata de acciones colectivas de desobediencia a una norma o ley, con la finalidad de que sean derogadas o dejadas sin efecto, se asiste a la desobediencia civil. Esta opone no sólo una fuerza psicológica y moral, sino también una oposición física pasiva a la imposición de la norma. Ejemplos de ello fueron "la marcha de la sal" promovida por Gandhi ${ }^{10}$, o la protesta multitudinaria contra las leyes segregacionistas de Birmingham, Estados Unidos, convocada por Martin Luther King ${ }^{11}$.

Cuando la intención es todavía más radical, y lo que se pone en tela de juicio es la misma legitimidad de la estructura normativa, nos encontramos frente a una voluntad revolucionaria.
Esta voluntad se podrá expresar en acciones de enfrentamiento con el orden establecido, que pueden escalar hasta una abierta y generalizada rebelión.

\section{La objeción de conciencia en la práctica médica}

En nuestro país la eventualidad de la objeción de conciencia ha surgido como tema de discusión a propósito de proyectos de ley sobre regulación jurídica de la práctica del aborto y de la eutanasia por parte de profesionales de la salud ${ }^{12-14}$. Debe considerarse que estas acciones estaban previamente definidas como delitos y penadas por la ley ${ }^{15}$. También esas acciones se encuentran tradicionalmente excluidas de la actividad profesional en los Códigos y Declaraciones de Ética Médica ${ }^{16-19}$. Sin embargo, la discusión ha adquirido un cariz diferente desde la aprobación de la ley que regula la despenalización de la interrupción voluntaria del embarazo en tres causales.

Como se hizo notar, tanto en la legislación vigente sobre el aborto, como en la propuesta en relación a la eutanasia,se deja constancia expresa acerca de la posibilidad de ejercer la acción de objeción de conciencia personal e institucional, y se la regula. Esta situación parecería contradictoria ya que en principio la objeción de conciencia es una acción de desobediencia a la ley, y la ley asume la obediencia general. Existen pocos estudios que exploren el significado real y las consecuencias posibles de esta 'desobediencia legalizada'.

\section{Reparos a la aceptación de la objeción de conciencia por parte de los médicos}

En contraste con la línea histórica de las discrepancias que hemos delineado, han aparecido opiniones, sobre todo desde fuera del ámbito médico, que sostienen que los profesionales de la salud no debieran estar autorizados a invocar la objeción de conciencia. El caso más emblemático de esta posición es la del filósofo de Oxford, Julian Savulescu ${ }^{20}$.

Savulescu argumenta que los determinantes del cuidado médico deben ser: la ley, la distribución justa de recursos limitados, los deseos informados de los pacientes y no los valores de los médicos ${ }^{21}$. Estima el autor que la objeción de conciencia en medicina es ineficiente y que conduce a inequidad. Esto porque al tener que buscar el paciente entre doctores que brindan diferentes servicios por razones de conciencia, pierden tiempo y re- 
cursos, a la vez que un paciente poco informado podría no recibir los servicios que le garantice la ley $^{22}$. Adicionalmente lo encuentra inconsistente, mencionando que si el preocuparse de la salud propia (al negarse, por ejemplo, en la atención de pacientes en una epidemia) es considerada una conducta no aceptable, no ve la razón para que la objeción moral sea válida en otros casos. También opina que el médico debe tener un compromiso con su profesión y hacer aquello que la misma le demanda en calidad de tal, a la vez que cree que los valores religiosos, considerados por algunos como especiales, no son más importantes que los seculares. De no ser así se produciría discriminación ${ }^{19}$. El autor acepta que el no permitir la objeción de conciencia podría dañar al médico y coartar su libertad, pero ello solo se puede aceptar si hay un número suficiente de médicos que puedan brindar el servicio requerido. Además menciona que esto es diferente en la práctica privada, donde un médico puede ofrecer los servicios que a él le parezcan los apropiados, informando adecuadamente a su paciente, pero eso no es aceptable en el servicio público ${ }^{23}$. Sostiene, finalmente, que tales acciones, por razones derivadas de habilidades y conocimientos específicos, deben ser llevadas a cabo por personas que desarrollan sus funciones en el área de la salud y no por otras personas, aunque sean entrenadas.

\section{Análisis de las objeciones}

Los planteamientos de Savulescu no carecen de lógica al interior de una particular visión de la vida social. En ese ámbito se distingue la esfera de lo estatal y la de lo privado, como si fuesen dos mundos separados.

En esa línea de pensamiento, en el ámbito de lo puramente privado el Estado no tendría injerencia ninguna sobre lo que acuerden las personas, salvo en aquellos aspectos que incidan en lo público, como serían por ejemplo la paz social, la tributación, y la obligación de responder a las exigencias administrativas generales como las de transparencia, regulación, certificación o acreditación.

En lo público,para Savulescu, el Estado sería una entidad éticamente neutra y las leyes emanadas de él derivarían su fuerza de imposición del cumplimiento formal de procedimientos legitimadores, denominados democráticos, cuya única función sería la de definir y expresar la voluntad mayoritaria. Voluntad que supuestamente exigiría sumisión en virtud de un cierto ideal democrático en el que predomina la razón instrumental y la fuerza del voto mayoritario, por sobre el respeto a las convicciones éticas personales.

\section{Respuestas teóricas a los planteamientos contrarios a la objeción de conciencia}

Frente a los radicales planteamientos de Savulescu caben dos tipos de respuestas: teóricas y prácticas.

En el orden teórico no es en absoluto evidente que la división organizativa entre la atención médica pública y la atención médica privada determine las distinciones éticas que se plantean, como tampoco es evidente que el ideal democrático liberal responda al sentido más genuino y tradicional de la democracia, que funda su legitimidad en la razón y no en la voluntad.

El ejercicio de las profesiones de la salud tiene siempre una dimensión pública porque se lleva a cabo en una comunidad política organizada, donde existen roles reconocidos, compromisos asumidos y responsabilidades comunes a todos los profesionales que participan directa o indirectamente en las acciones de salud. Estos mismos profesionales son los proveedores directos de las atenciones de salud, tanto en el llamado sistema estatal como en el llamado sistema privado. La sociedad, por medio de sus costumbres, tradiciones, instituciones, leyes y tribunales de justicia reconoce la personal e intransferible responsabilidad individual de estos profesionales, en función tanto de sus conocimientos técnicos y habilidades, como del cumplimiento de su ética profesional en el ámbito cívico.

En la realidad de la práctica no es el sistema el que atiende, son las personas individuales, solas o en equipos de salud. Fiel reflejo de ello es por ejemplo el Derecho Penal que exige la responsabilidad "personalísima" de los profesionales con independencia del sistema en el cual ellos ejerzan. Otra prueba de lo afirmado es que las Escuelas que forman para las carreras de la salud, lo hacen sin diferenciación del tipo de ejercicio profesional que sus egresados practicarán, sea éste en el ámbito público o privado.

La fidelidad de cada profesional a su lex artis, que integra tanto lo ético como lo técnico, es garantía de la calidad de la atención entregada, $y$ es frente a ella que será juzgado éste cuando contravenga gravemente a sus responsabilidades 
y obligaciones. El profesional de la salud,entonces, no puede convenir con su paciente nada que contraríe a su lex artis, sea donde sea que ejerza. La sociedad espera que los profesionales se atengan a esa ley, la que ciertamente está sujeta a adaptaciones y progresos debatibles racionalmente. El objetor de conciencia invoca aquella fidelidad, sin que esté moralmente obligado a supeditar esa fidelidad a consideraciones de orden pragmático.

$\mathrm{Al}$ velar por el bien de las personas, ni la sociedad en su conjunto, ni el Estado que es su instrumento, pueden ser éticamente neutros -como pretenden algunas concepciones modernas-, y es por ello que el Estado está moralmente obligado a promover y favorecer el que los profesionales puedan cumplir con sus obligaciones, debiendo perseguirlos y sancionarlos legalmente cuando las contrarían de modo evidente y flagrante.

\section{Objeciones prácticas a los planteamientos contrarios a la objeción de conciencia}

Cuando se argumenta que los determinantes del cuidado médico deben ser: la ley, la distribución justa de recursos limitados y los deseos informados de los pacientes -y no los valores de los médicos-se asume que los profesionales de la salud actuarían, al objetar, siguiendo valores propios que serían distintos a los de la sociedad en su conjunto. En esa hipótesis, la ley, las consideraciones económicas y los deseos de los pacientes, serían mejores intérpretes de la voluntad común que los profesionales individuales de la salud.

Los hechos no se condicen con estas suposiciones. Los profesionales de la salud, en principio, comprenden las necesidades específicas y comparten las preocupaciones concretas de los pacientes de modo mucho más cercano que las instancias generales señaladas. Salvo situaciones puntuales, que se dan en todos los niveles,es razonable sostener que-salvo prueba en contrario-la sociedad puede confiar en el criterio de estos profesionales, cuando este criterio viene además respaldado por estudios, experiencia e integridad.

Ante la realidad de un grupo importante de profesionales con capacidad técnica, experiencia y éticamente confiables, que estiman que una determinada acción promovida desde instancias normativas es nociva para la salud física, psíquica y moral de sus pacientes, de la sociedad en general, y de los profesionales de la salud, aparece como razonable otorgarles el beneficio de la duda a tra- vés de la objeción de conciencia, al evidenciarse el conflicto con las prácticas del arte médico.

Más aún, se echa de menos, por parte de la sociedad, un cuestionamiento crítico, desapasionado y desideologizado acerca de la racionalidad y la conveniencia de mantener la aplicación de esas acciones que son motivo de objeción. Los objetores no objetan porque busquen un bien o una ventaja personal, lo hacen porque estiman que se encuentra en juego el bien individual de sus pacientes, su integridad moral y el bien común de la sociedad.

El desconocimiento de las motivaciones que mueven a los que objetan,como la caricaturización acerca de sus finalidades, no contribuye a forjarse una idea adecuada de los verdaderos problemas que están en juego en estas circunstancias. Por otra parte, la distinción entre una ética de lo público y una de lo privado ha conducido a una exacerbación del control legal, económico y social sobre la vida personal tendiendo a reducirla más allá de lo razonable. No es en absoluto claro que existan dos éticas distintas, la pública y la privada, es la misma ética que se ejerce en ámbitos diversos.

Para poder determinar con certeza la implicancia pública de las acciones privadas la sociedad tecnocrática moderna se ha visto entrampada en una lógica que conduce a intentar saber, regular, certificar, en definitiva, controlar lo máximo posible.

Frente a esta actitud de la voluntad general, la libertad de las personas y sus espacios de autonomía se ven importantemente amagadas, sobre todo frente a aquellas acciones que la ley impone sin atender a circunstancias que derivan del conocimiento informado y experto de las realidades particulares por parte de profesionales idóneos.

\section{Conclusiones}

La objeción de conciencia aparece en la sociedad occidental contemporánea como una figura político-jurídica de contornos todavía imprecisos, pero que ha ido adquiriendo progresivamente legitimidad.

En nuestro país ciertas normativas jurídicas que inciden en el campo de acción de los profesionales de la salud, han generado discrepancias de orden moral que han encontrado un cauce a través de la objeción de conciencia.

Desde algunos ámbitos de poder, sean éstos de 
tipo estatal, económico, jurídico o mediático, se percibe cierta resistencia a aceptar el pleno ejercicio de la objeción de conciencia por parte de los profesionales de la salud. Las polémicas públicas en torno al alcance y límites de la objeción de conciencia dan fe de esta incomodidad.

El examen que se ha hecho de la historia y de la naturaleza de la objeción de conciencia parece indicar que la sociedad no sólo debiese tolerar esta reivindicación por parte de estos profesionales, sino que debiera reflexionar acerca de las razones de fondo que los llevan a ejercerla. Más aún cuando la proporción de los aludidos aparece como significativa, como es el caso ante la ley de aborto ${ }^{24}$.

La objeción de conciencia legalmente reconocida-como acción civilizada que es-, se erige hoy como un último recurso frente a una determinación del poder que se considera que atenta contra aquello de más valioso que radica en la persona, según lo juzga la propia conciencia.

\section{Referencias}

1. República de Chile. Ley núm. 20.130, del 23 de septiembre de 2017. Regula la despenalización de la interrupción voluntaria del embarazo en tres causales. Disponible en: https://www.leychile.cl/Navegar?idNor$\mathrm{ma}=1108237 \&$ buscar $=$ interrupcion + del + embarazo (Consultado el 4 de abril de 2019).

2. Cf. La polémica suscitada a mediados de 2018 entre dos distinguidos juristas y actores políticos los profesores Carlos Peña y Hernán Larraín, en el diario El Mercurio de Santiago, acerca de las consecuencias jurídicas de la aceptación "legal" de la no obediencia a la ley.

3. Aristóteles. Política. I, 1253a, 12. Gredos, Madrid. 2a reimpresión, 1999.

4. Rodríguez Luño, A. Ética General.5ª. Ed. EUNSA, Pamplona, 2004. Cap. VIII.

5. S. Tomás de Aquino. S. Th., I-II. q. 55 y q.94. BAC. Madrid, 2001.

6. República de Chile. Constitución Política. Art. 19, núm. 6. Disponible en: https://www.leychile.cl/Navegar?idNorma=242302 (Consultado el 30 de marzo de 2019). Es interesante señalar que: la moral, las buenas costumbres y el orden público aparecen como condiciones básicas del orden jurídico.

7. Naciones Unidas. Declaración Universal de los Derechos Humanos. 1948. Disponible en: http://www.ohchr.org/ EN/UDHR/Documents/UDHR_Translations/spn.pdf (Consultado el 19 de marzo de 2019).
8. Real Academia Española. Diccionario de la Lengua Española. 23a. Edición. 2014.

9. Agustín Squella Narducci. Introducción al Derecho. Legal Publishing Chile, Santiago de Chile, 2014. Pág.104.

10. A. de Blas R. La Marcha de la sal. Archivos Historia. 12-Marzo de 2019. Disponible en: https://archivoshistoria.com/marcha-de-la-sal/ (Consultado el 4 de abril de 2019).

11. Martin Luther King. Letter from a Birmingham Jail. April 16, 1963. Disponible en: http://okra.stanford.edu/ transcription/document_images/undecided/630416-019. pdf.

12. Beca JP. La discusión sobre el aborto en Chile. Rev Chil Pediatr 2014; 85 (4): 418-20.

13. Besio M. Proyecto de ley sobre despenalización del aborto: análisis ético. Rev Chil Obstet Ginecol 2015; 80 (2): $175-80$

14. Molina R. Aspectos bioéticos del aborto en Chile. Rev Chil Obstet Ginecol 2013; 78: 259-61.

15. República de Chile. Código Penal. Arts. 342 y 343. Disponible en: https://www.leychile.cl/Navegar?idNor$\mathrm{ma}=1984 \&$ buscar $=$ codigo + penal $($ Consultado el 5 de abril de 2019).

16. Colegio Médico de Chile. Código de Ética. 2013. Disponible en: http://www.colegiomedico.cl/wp-content/ uploads/2018/12/colmed_codigo_etica_2013.pdf (Consultado el 1 de abril de 2019).

17. Organización Médica Colegial de España. Comisión Central de Deontología. Declaraciones 2000-2017. Disponible en: https://www.cgcom.es/sites/default/files/ declaraciones_ccd_2017/index.html (Consultado el 15 de marzo de 2019).

18. Asociación Médica Mundial. Declaración sobre el término del embarazo por indicación médica. Nov., 15, 2018. Disponible en: https://www.wma.net/es/policies-post/ declaracion-de-oslo-de-la-amm-sobre-el-aborto-terapeutico/ (Consultado el 1 de abril de 2019).

19. Asociación Médica Mundial. Declaración de la AMM sobre la eutanasia. Mar. 22, 2017. Disponible en: https://www.wma.net/es/policies-post/declaracion-dela-amm-sobre-la-eutanasia/ (Consultado el 1 de abril de 2019).

20. Director, Centre for Practical Ethics, University of Oxford.

21. Savulescu J. Conscientious objection in medicine. BMJ 2006; 332: 294-7.

22. Ibid. 18. p. 295.

23. Ibid. 18, p. 296.

24. Aborto: $50 \%$ de los obstetras de la red pública se declara objetor de conciencia en casos de violación. La Tercera, 10-Junio-2019. 